\title{
LATE AUTOGRAFT AND HOMOGRAFT ENDOCARDITIS AFTER THE ROSS OPERATION
}

\author{
Alain Prat, MD, ${ }^{\mathrm{a}}$ José Saez de Ibarra, MD, ${ }^{\mathrm{a}}$ André Vincentelli, MD, ${ }^{\mathrm{a}}$ Christophe Decoene, MD, ${ }^{\mathrm{b}}$ \\ Christine Savoye, $\mathrm{MD},{ }^{\mathrm{c}}$ and Yves Goffin, $\mathrm{MD},{ }^{\mathrm{d}}$ Lille, France, and Brussels, Belgium
}

Pulmonary autografts and left- and right-sided cryopreserved homografts are widely known for their resistance to infection. ${ }^{1-3}$ We report here on the first case of endocarditis occuring in one of 86 patients who underwent aortic root replacement with a pulmonary autograft at our institution between March 1992 and December 1997.

Clinical summary. A 34-year-old man with congenital bicuspid aortic valve stenosis and no history of endocarditis underwent elective aortic root replacement with a pulmonary autograft (Ross procedure) in October 1992. The right ventricular outflow tract (RVOT) was reconstructed with a cryopreserved pulmonary homograft provided by the European Homograft Bank. The patient's postoperative course was uneventful and he was periodically monitored at our institution by clinical examination and Doppler echocardiography. At his most recent examination, in October 1996, Doppler echocardiographic analysis showed normal autograft and homograft function.

The patient was readmitted to the hospital 4.3 years after the Ross procedure, in January 1997, with fever and left-sided congestive heart failure caused by active endocarditis causing aortic insufficiency. Initial transesophageal echocardiography revealed grade 2 autograft regurgitation, and a small vegetation ( 2 by $5 \mathrm{~mm}$ ) was found on the left coronary cusp. The mitral, tricuspid, and pulmonary valves were all normal. Blood cultures showed Streptococcus gordonii, with anamnesis revealing a dental pro-

From the Departments of Cardiac Surgery, ${ }^{\mathrm{a}}$ Anesthesiology, and the Echocardiography and Ultrasound Laboratory, ${ }^{\mathrm{c}}$ Lille University Heart Center, Lille, France, and the European Homograft Bank, ${ }^{\mathrm{d}}$ Brussels, Belgium.

Received for publication Jan. 7, 1998; accepted for publication Jan. 13, 1998.

Address for reprints: A. Prat, MD, Service de Chirurgie Cardiaque, Hôpital Cardiologique-CHRU, 59037 Lille Cedex, France.

J Thorac Cardiovasc Surg 1998;115:1388-9

Copyright () 1998 by Mosby, Inc.

0022-5223/98 $\$ 5.00+0 \quad \mathbf{1 2 / 5 4 / 8 8 8 1 7}$ cedure (scaling), without antibiotic prophylaxis, 3 weeks before the patient's readmission to the hospital.

The patient was first treated with appropriate antibiotics (ampicillin $12 \mathrm{~g} / 24 \mathrm{hr}$ intravenously, given continuously, and gentamicin $1 \mathrm{mg} / \mathrm{kg}$ intravenously every 8 hours). However, after 10 days, surgical treatment was considered because of a persistent inflammatory syndrome and hemodynamic deterioration. Magnetic resonance imaging of the brain and abdominal computed tomographic densitometry scans revealed no metastatic infection. A second transesophageal echocardiogram showed the progressive development of lesions on the autograft with a resulting grade 3 regurgitation and detected a vegetation ( 5 by $15 \mathrm{~mm}$ ) on the posterior leaflet of the right-sided pulmonary homograft.

The patient underwent surgery 24 hours later. Intraoperative transesophageal echocardiography was performed immediately before the start of cardiopulmonary bypass and showed a dramatic increase in autograft and homograft lesions. Pathologic observations corresponding to the echocardiographic appearance were noted during the operation. Two cusps of the autograft were torn, with a 5 by $8 \mathrm{~mm}$ vegetation on the left coronary cusp and an 8 by $10 \mathrm{~mm}$ vegetation on the right coronary cusp. The noncoronary cusp was unaffected and absolutely normal, and there was no annular or perivalvular involvement. The pulmonary homograft was extensively damaged, and the RVOT was obstructed by large cauliflower-shaped vegetations. All left- and right-sided suture lines from the previous operation were healed.

All infected and necrotic tissue was excised, such that the autograft wall was conserved while the homograft wall was completely removed. Inasmuch as no homografts were available at the time of the operation, the autograft valve was replaced with a mechanical prothesis $(27 \mathrm{~mm}$, St. Jude Medical, Inc., St. Paul, Minn.) and the RVOT was reconstructed with a stentless porcine bioprosthesis $(27 \mathrm{~mm}$ Medtronic Freestyle bioprosthesis, Medtronic Inc., Minneapolis, Minn.). Streptococcus gordonii was cultured from the vegetations excised from both valves. Fungal endocarditis was not documented on the pulmonary homograft. Microscopic studies of the excised cusps from the autograft showed no calcification, normal cellularized fragments, and few foci 
of fibrinoid necrosis with some colonies of gram-positive cocci. An examination of the pulmonary homograft remnants showed a devitalized tissue covered with a fibrous pannus and some calcifications. Antibiotics were continued intravenously for 6 weeks. Ten months after the operation the patient was alive and doing well, in New York Heart Association class I, with well-functioning prostheses, apparently cured of the infection.

Discussion. The incidence of late autograft endocarditis ( $>1$ year) after a Ross procedure is very low. In the pioneering studies of Donald Ross, positively identified autograft infections occurred in just three of the 131 patients involved, these being at 3, 10, and 15 years, respectively, after the autograft procedures had been performed. ${ }^{4}$ Elkins, Lane, and $\mathrm{McCue}^{1}$ reported only one case of late autograft endocarditis among 195 operative survivors of the Ross operation, this occurring 6.2 years after the procedure.

Infective endocarditis involving the homograft in the pulmonary position has, at best, rarely been reported after the Ross procedure. We found only one case in the work of Chambers, Somerville, Stone, and Ross ${ }^{4}$ and no cases reported in the study by Elkins, Lane, and McCue. ${ }^{1}$ In the study of Bando and coworkers, ${ }^{3}$ no case of infective endocarditis occurred among 326 patients who received aortic or pulmonary cryopreserved homografts for RVOT reconstruction between January 1985 and October 1993. The pulmonary valve is the least commonly affected valve in infective endocarditis, with most cases having been reported in patients with predisposing factors, such as drug addiction or underlying congenital heart disease. Furthermore, in patients with primary pulmonary valve endocarditis, involvement of left-sided valves is very uncommon..$^{5}$ To the best of our knowledge, we report here the first case of autograft and homograft endocarditis after a Ross procedure. We were unable to identify a predisposing factor such as valvular dysfunction in our patient. We were surprised by the extensive and rapidly evolving damage to the pulmonary homograft compared with the relatively localized lesions on the autograft. The findings could be explained by the viability of the autograft.

Inasmuch as the frequency of bacteremia after dental procedures is high, the administration of appropriate antibiotic prophylaxis should not be neglected in patients having undergone heart valve replacement, inclusive of the Ross procedure.

\section{REFERENCES}

1. Elkins RC, Lane MM, McCue C. Pulmonary autograft reoperation: incidence and management. Ann Thorac Surg 1996; 62:450-5.

2. Prat AG, Doisy VC, Savoye C, Moreau DC, Monier EJ, Stankowiak C. Total aortic root replacement with pulmonary autografts: short term results in 45 consecutive patients J Heart Valve Dis 1995;4:368-73.

3. Bando K, Danielson GF, Schaff HV, Mair DD, Julsrud PR, Puga FJ. Outcome of pulmonary and aortic homografts for right ventricular outflow tract reconstruction. J Thorac Cardiovasc Surg 1995;109:509-18.

4. Chambers JC, Somerville J, Stone S, Ross DN. Pulmonary autograft procedure for aortic valve disease: long term results of the pioneer series. Circulation 1997;96:2206-14.

5. Cremieux AC, Witchitz S, Malergue MC, Wolff M, Vittecocq D, Vilde JL, et al. Clinical and echocardiographic observations in pulmonary valve endocarditis. Am J Cardiol 1985;56:610-3. 